\title{
Poly (Vinyl Alcohol) Decorated Lithium Doped Stannous Oxide Nanocomposites as Highly Flexible UVA Shieldants
}

\author{
Nithin $\mathbf{S K}^{1,2}$, Shivanna $\mathbf{S}^{1}$, Shilpa Nagaraj $\mathbf{K}^{1}$, Chiranjeevi ${ }^{1}$, Ranjith ${ }^{1}$, Chinmayee $\mathbf{S}^{1}$ and Basavarajaiah $\mathbf{S}^{1 *}$
}

${ }^{1}$ Department of Polymer Science and Technology, Sri Jayachamarajendra College of Engineering, Mysuru-570 006, Karnataka, India ${ }^{2}$ Postgraduate Department of Chemistry, JSS College, Mysuru-570 025, Karnataka, India

\begin{abstract}
Herein, we report the successful fabrication of a series of mechanically flexible poly (vinyl alcohol) (PVA) nanocomposite films with varying amounts of lithium doped stannous oxide (LiO.4SnO.8O) nanofillers (i.e., $0.0,0.5$, 1.0, 2.0 and $4.0 \mathrm{wt} \%$ ) by mechanical shearing followed by film casting. The structural characterizations (FTIR) ascertain the success of lithium doped stannous oxide integrations with PVA matrix. While, electronic spectral studies sheds light on the changes in electronic band structure leading to a gradual decrease in optical band gaps associated electronic transition from valence band to conduction band. The UV-visible transmittance study substantiates the ability of nano fabricated polymeric films to efficiently shield UV radiations, in particular UVA radiations and thereby act as highly flexible and visible transparent UVA protective coatings.
\end{abstract}

Keywords: UVA protective coatings; Lithium doped stannous oxide; Nano composite

\section{Introduction}

High energy ultra violet (UV) photons are known to affect interesting scientific and technological applications. In contrary, UV radiations also brings about severe biological and material vandalizations including damage of genetic material (DNA), Immune suppressions and skin photo aging, in addition to significant material damages. The observed degradation effects is owed to the sufficiently high energy of UV photons that brings about significant physicochemical changes in the material under study, leading to rapid photolytic and photo oxidative properties ensuing significant loss in material properties [1], which, in turn has led the scientific community towards the design and development of organic UV absorbers that acts as UV shieldants by transforming the absorbed high energy UV radiations into the less damaging phonons through various photo physical processes $[2,3]$. However, the organic UV absorbers are prone to weathering effects, thereby limiting their technological applications.

In recent years, organic-inorganic composite materials are being increasingly investigated as advanced technological materials for opto-electronic device fabrications, owing to their unique mechanical, photoelectric and thermal properties, arising from the synergistic filler (inorganic) - matrix (organic) interactions. In last few decades, the scientific community has been able to impose entirely new material properties on conventional materials by manipulation of matter at molecular levels. The molecular level engineering of matter facilitates a larger surface area which in turn accounts for the advanced material properties of nano sized materials in contrast to the bulk in accordance with earlier reports [4-9]. In the midst of the various physico-chemical properties of polymer nanocomposites, barrier protection against high energy UV radiations is of significant interest. In this context, many efforts have been addressed in the development of visibly transparent polymeric matrices with appreciable UV-shielding properties to be employed as UV protective coatings and optical filters [10-13].

Typically, metal oxide nanoparticles are integrated onto particle stabilizing polymers, allowing the preparation of hybrid nanocomposites with appreciable UV-shielding capabilities. These nanoparticles have been applied as UV-absorbing materials, owing to their low cost, and good environmental stability in addition to reduced toxicities. Thus, in the present research investigation, an attempt is made to induce UVA shielding properties in highly flexible and visible transparent poly (vinyl alcohol) (PVA) matrix to be employed as UVA protective coatings.

\section{Experimental Methods}

Lithium doped stannous oxide $\left(\mathrm{Li}_{0.4} \mathrm{Sn}_{0.8} \mathrm{O}\right)$ nanoparticles have been prepared by a previously reported gel combustion technique with slight modifications. The PVA/ $\mathrm{Li}_{0.4} \mathrm{Sn}_{0.8} \mathrm{O} \mathrm{NC}$ films were developed by suitably dissolving varying weight fractions of $\mathrm{Li}_{0.4} \mathrm{Sn}_{0.8} \mathrm{O}$ nano fillers. The resultant solutions were subjected to mechanical shearing followed by ultra sonication, so as to achieve uniform filler dispersions. The homogenized PVA/ $\mathrm{Li}_{0.4} \mathrm{Sn}_{0.8} \mathrm{O}$ aqueous solutions were then casted onto clean glass molds and allowed to dry under ambient atmosphere. The fabricated visibly transparent nano composites with a thickness of 0.30-0.34 mm were subjected to spectral characterizations.

The Fourier Transform Infrared (FTIR) spectrum of the PVA and its PVA/ $\mathrm{Li}_{0.4} \mathrm{Sn}_{0.8} \mathrm{O}$ nanocomposite (NC) films analogues were recorded in the spectral wave number range $4000-400 \mathrm{~cm}^{-1}$ using JASCO 4100 spectrometer, Japan, with a maximum resolution of 0.9 $\mathrm{cm}^{-1}$. The electronic spectral details of fabricated films were established by Schimadzu-1800 spectrophotometer, Japan, in the spectral range of 200-800 nm.

\section{Results and Discussion}

The Fourier Transform Infrared spectroscopic (FTIR) studies of pristine PVA and its $4 \mathrm{wt} \% \mathrm{Li}_{0.4} \mathrm{Sn}_{0.8} \mathrm{O}$ nanofiller introduced composite film (Figure 1) reveals Infrared (IR) band around $932 \mathrm{~cm}^{-1}$ symbolizing the highly planar syndiotactic structure of PVA with a sequential

*Corresponding author: Siddaramaiah Basavarajaiah, Department of Polymer Science and Technology, Sri Jayachamarajendra College of Engineering, Mysuru-570 006, Karnataka, India, E-mail: siddaramaiah@gmail.com

Received March 14, 2016; Accepted March 15, 2016; Published March 21, 2016

Citation: Nithin SK, Shivanna S, Nagaraj KS, Chiranjeevi, Ranjith, et al. (2016) Poly (Vinyl Alcohol) Decorated Lithium Doped Stannous Oxide Nanocomposites as Highly Flexible UVA Shieldants. Chem Sci J 7: 121. doi:10.4172/2150-3494.1000121

Copyright: ( 2016 Nithin SK, et al. This is an open-access article distributed under the terms of the Creative Commons Attribution License, which permits unrestricted use, distribution, and reproduction in any medium, provided the original author and source are credited. 
distribution of -OH groups [14]. However, filler introduction leads to appreciable changes in the planarity of composite films with a blue shift towards $920 \mathrm{~cm}^{-1}$, thereby inducing novel opto-electronic properties in contrast to the planar syndiotactic PVA films. The introduced nano filler also induces a considerable decline in intensities of $-\mathrm{OH}$ stretching vibrations, indicating a synergistic interaction between -OH groups of PVA matrix, with metallic fractals of $\mathrm{Li}_{0.4} \mathrm{Sn}_{0.8} \mathrm{O}$ nano fillers [15]. The $\mathrm{Li}_{0.4} \mathrm{Sn}_{0.8} \mathrm{O}$ nano fillers also affected a continuous decrease in IR band intensities in the wave number regimes $1510-1075 \mathrm{~cm}^{-1}$, owing to the decoupling of $-\mathrm{OH}$ and $-\mathrm{CH}$ vibrations. The UV-visible absorbance spectrum of PVA/ $\mathrm{Li}_{0.4} \mathrm{Sn}_{0.8} \mathrm{O}$ nanocomposite films (Figure 2) reveals the effect of nano filler introductions on electronic band structure of composite films with a broad shouldered valley around 260-280 nm. In contrast, the nanocomposite films display additional UVA absorption band around 320-330 $\mathrm{nm}$ due to $\mathrm{Li}_{0.4} \mathrm{Sn}_{0.8} \mathrm{O}$ loadings [16].

The electronic spectral studies also support the UVA shielding abilities of nanocomposite films, while retaining transparencies in visible region (Figure 3). The increased UVA shielding abilities of developed films may be attributed to the incorporation of UVA absorbing $\mathrm{Li}_{0.4} \mathrm{Sn}_{0.8} \mathrm{O}$ nanofiller (Figure 4). The excellent visible transparencies of $\mathrm{PVA} / \mathrm{Li}_{0.4} \mathrm{Sn}_{0.8} \mathrm{O}$ nanocomposites may also be attributed to extremely smaller filler domains and near matching fillermatrix refractive indices that reduces the scattering losses $[17,18]$. The optical energy gap is the determinant factor that key establishes the portion of sunlight absorbed by a photovoltaic device leading to increased photovoltaic conversion efficiencies. The Figure 4 shows a

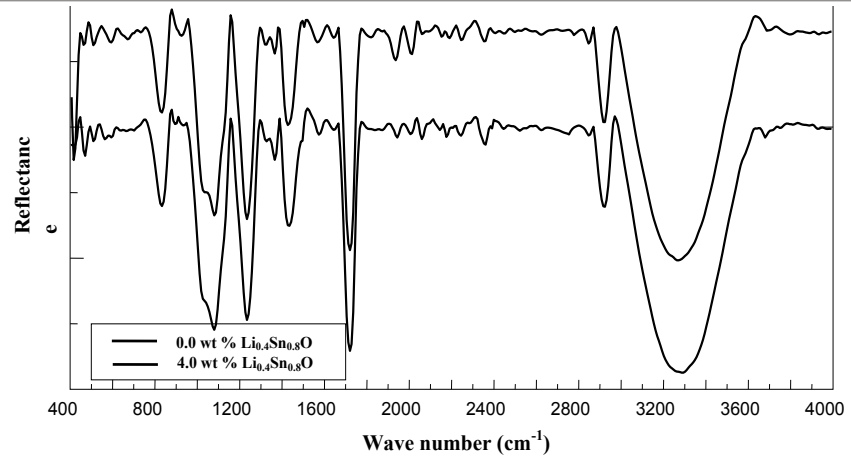

Figure 1: FTIR reflectance spectra of PVA nanocomposite films with (a) 0 , (b) 0.5 , (c) 1.0 , (d) 2.0 , and (e) 4.0 wt \% of $\mathrm{Li}_{0.2} \mathrm{Sn}_{0.8} \mathrm{O}$.

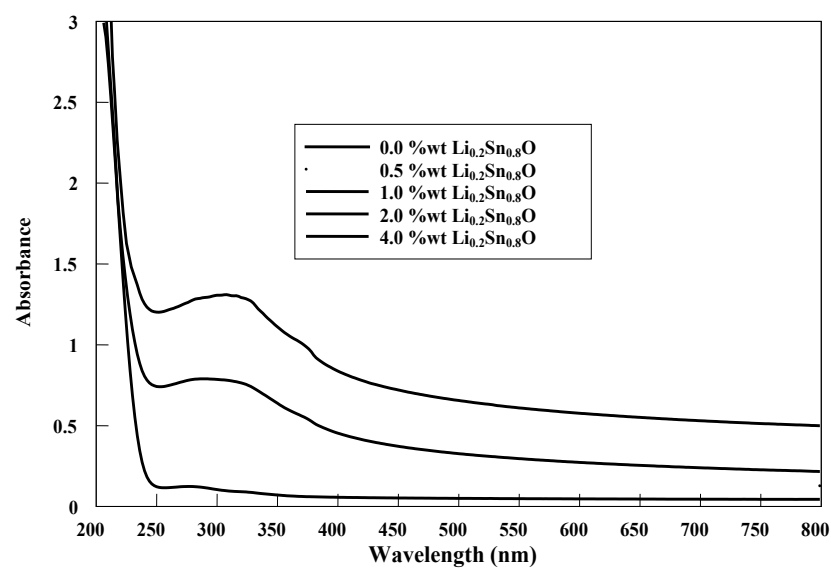

Figure 2: UV-visible absorbance spectra of PVA nanocomposites with (a) 0 , (b) 0.5 , (c) 1.0, (d) 2.0, and (e) $4.0 \mathrm{wt} \%$ of $\mathrm{Li}_{0.2} \mathrm{Sn}_{0.8} \mathrm{O}$.

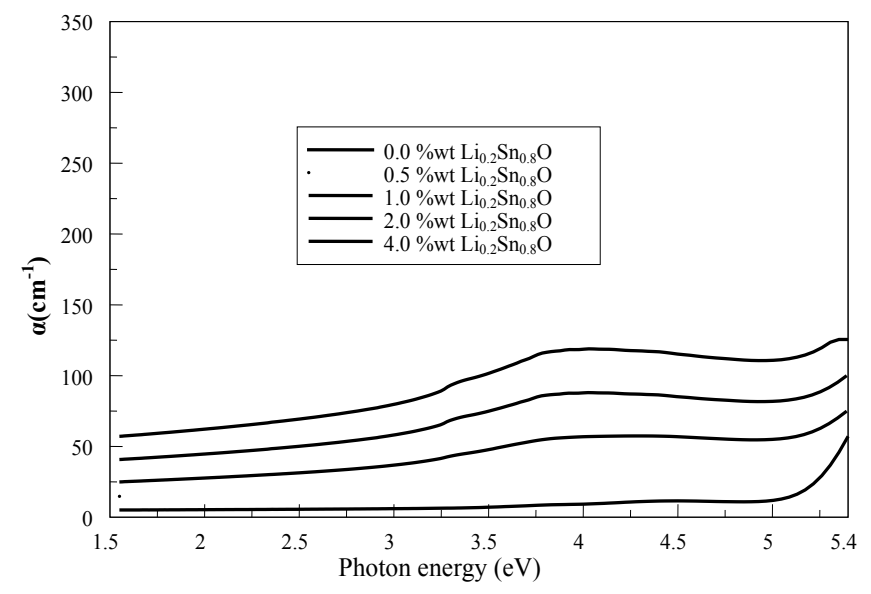

Figure 3: Absorption coefficient vs photon energy of PVA $\mathrm{Li}_{0.2} \mathrm{Sn}_{0.8} \mathrm{O}$ nanocomposites.

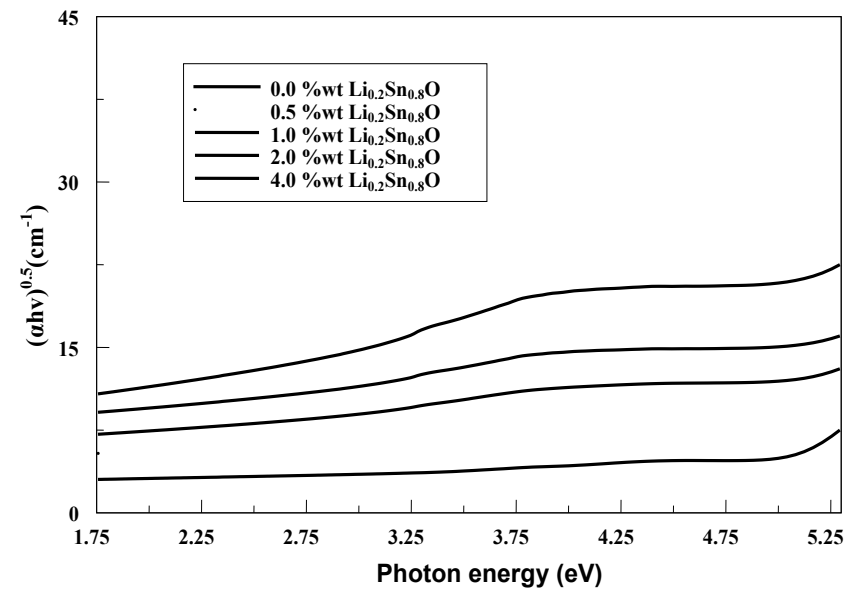

Figure 4: Tauc's plot for the determination of direct band gaps.

monotonic dependence of optical band gaps on nanofiller content, with energies allied to inter band electronic transitions showing a steady decrease nanofiller loadings. The observed variation in optical energy gap reveals a change in the optical band structure of PVA films upon nanofiller intercalations due to formation of polarons in the $\mathrm{Li}_{0.4} \mathrm{Sn}_{0.8} \mathrm{O}$ introduced PVA films [19,20].

\section{Conclusion}

In summary, highly flexible and visibly transparent PVA nanocomposite films were fabricated with lithium doped stannous oxide nanofillers by aqueous solvent casting method. The introduced nano fillers were found to be well dispersed throughout the PVA matrix thereby retaining high visible transparencies $(550 \mathrm{~nm})$. In addition, the introduced fillers affected a continuous reduction in energies associated with inter-band electronic transitions leading to novel opto-electronic properties with enhanced UVA shielding efficacies.

\section{References}

1. Wei Q, Lee JE, Gershenwald JE, Ross MI, Mansfield PF, et al. (2003) Repair of UV light-induced DNA damage and risk of cutaneous malignant melanoma. J Natl Cancer Inst 95: 308-315.

2. Ullrich SE (2005) Mechanisms underlying UV-induced immune suppression. Mutat Res 571: 185-205. 
Citation: Nithin SK, Shivanna S, Nagaraj KS, Chiranjeevi, Ranjith, etal. (2016) Poly (Vinyl Alcohol) Decorated Lithium Doped Stannous Oxide Nanocomposites as Highly Flexible UVA Shieldants. Chem Sci J 7: 121. doi:10.4172/2150-3494.1000121

3. Hanson KM, Simon JD (1998) Epidermal trans-urocanic acid and the UV-Ainduced photoaging of the skin. Proc Natl Acad Sci USA 95: 10576-10578.

4. Zayat M, Garcia-Parejo P, Levy D (2007) Preventing UV-light damage of light sensitive materials using a highly protective UV-absorbing coating. Chem Soc Rev 36: 1270-1281.

5. Elahe A, Karimi-Maleh H, Pahlavan A, Vahedi J (2013) Electrochemical behavior of morphine at $\mathrm{ZnO} / \mathrm{CNT}$ nanocomposite room temperature ionic liquid modified carbon paste electrode and its determination in real samples. $\mathrm{J}$ of Molec Liq 181: 8-13.

6. Beitollah H, Goodarzian M, Mohd Khalilzadeh A, Karimi-Maleh H, Hassanzadeh $\mathrm{M}$, et al. (2012) Electrochemical behaviors and determination of carbidopa on carbon nanotubes ionic liquid paste electrode. J of Molec Liq 173: 137-143.

7. Ensafi AA, Karimi-Maleh H, Mallakpour S, Hatami M (2010) Simultaneous determination of $\mathrm{N}$-acetylcysteine and acetaminophen by voltammetric method using $\mathrm{N}$-(3,4-dihydroxyphenethyl)-3,5-dinitrobenzamide modified multiwall carbon nanotubes paste electrode. Sens and Actu B: Chem 155: 464-472.

8. Karimi-Maleh H, Biparva P, Hatami M (2013) A novel modified carbon paste electrode based on NiO/CNTs nanocomposite and (9, 10-dihydro-9, 10-ethanoanthracene-11, 12-dicarboximido)-4-ethylbenzene-1, 2-diol as a mediator for simultaneous determination of cysteamine, nicotinamide adenine dinucleotide and folic acid. Biosen and Bioelec 48: 270-275.

9. Ensafi AA, Karimi-Maleh H (2010) Modified multiwall carbon nanotubes paste electrode as a sensor for simultaneous determination of 6-thioguanine and folic acid using ferrocenedicarboxylic acid as a mediator. $\mathrm{J}$ of Elec Analy Chem 640: 75-83.

10. Mosquera M, Penedo JC, Ríos Rodríguez MC, Rodríguez-Prieto F (1996) Photoinduced inter-and intramolecular proton transfer in aqueous and ethanolic solutions of 2-(2'-hydroxyphenyl) benzimidazole: evidence for tautomeric and conformational equilibria in the ground state. Jour of Phy Chem 100: 5398-5407.
11. Keck J, Roessler M, Schroeder C, Stueber GJ, Waiblinger F, et al. (1998) Ultrviolet Absorbance of the 2-(2- Hydroxyaryl)-1, 3, 5-Triazine class and their methoxy derivatives-fluorescence spectroscopy and X-ray structure-analysis. $J$ Phys Chem B 102: 6975-6985.

12. Parejo PG, Zayata M, Levy D (2006) Highly efficient UV-absorbing thin-film coatings for protection of organic materials against photo degradation. J Mater Chem 16: 2165-2169.

13. Calvo ME, Castro Smirnov JR, Miguez H (2012) Novel approaches to flexible visible transparent hybrid films for ultraviolet protection. Journal of Polymer Science Part B-Polymer Physics 50: 945-956.

14. Chandrakala HN, Ramaraj B, Shivakumaraiah S, Siddaramaiah H (2014) Optical Properties and Structural Characteristics of Zinc oxide - cerium Oxide Doped Polyvinyl alcohol films. J Alloy and Comp 586: 333-342.

15. Nithin KS, Siddaramaiah H (2015) Opto-Electrical Characteristics of Poly (viny alcohol)/Cesium Zincate Nanodielectrics. J Phys Chem C 119: 20244-20255.

16. Tu Y, Zhou L, Jin YZ, Gao C, Ye ZZ, et al. (2010) Transparent and Flexible Thin Films of ZnO-Polystyrene Nanocomposite for UV Shielding Applications. J Mater Chem 20: 1594-1599.

17. Abdelaziz M, Ghannam MM (2010) Influence of Titanium Chloride Addition on the Optical and Dielectric Properties of PVA films. Physica B 405: 958-964.

18. Smirnov JRC, Calvo ME, Miguez H (2013) Selective UV Reflecting Mirrors Based on Nanoparticle Multilayers. Adv Funct Mater 23: 2805-2811.

19. Rao Y, Chen S (2008) Molecular Composites Comprising $\mathrm{TiO} 2$ and their Optical Properties. Macro 41: 4838-4844.

20. Nithin KS, Shilpa Nagaraj K, Shivanna S, Siddaramaiah H (2016) Highly Flexible and Visibly Transparent Poly (vinyl alcohol)/Calcium Zincate Nanocomposite Films for UVA Shielding Applications As Assessed by Novel Ultraviolet Photon Induced Fluorescence Quenching. ACS Macro. 